\title{
Small Volume Dissolution Testing as a Powerful Method during Pharmaceutical Development
}

\author{
Scheubel Emmanuel ${ }^{1,2, *}$, Lindenberg Marc ${ }^{2}$, Beyssac Eric ${ }^{1}$ and Cardot Jean-Michel ${ }^{1}$
}

1 Biopharmaceutical department, Faculty of Pharmacy, University of Auvergne 28 Place H. Dunant, BP 38, 63001 Clermont-Ferrand, France; E-Mails: eric.beyssac@u-clermont1.fr (B.E.) ; j-michel.cardot@u-clermont1.fr (C.J.-M.)

2 Galenical \& Analytical Development, Pharmaceutical Division, F. Hoffmann-La Roche Ltd., CH4070, Basel, Switzerland; E-Mail: marc.lindenberg@roche.com (L.M.)

* Author to whom correspondence should be addressed; E-Mail: emmanuel.scheubel@ roche.com; Tel.: +41616886357; Fax +41616870280.

Received: 12 October 2010; in revised form: 26 October 2010 / Accepted: 28 October 2010 / Published: 1 November 2010

\begin{abstract}
Standard compendia dissolution apparatus are the first choice for development of new dissolution methods. Nevertheless, limitations coming from the amount of material available, analytical sensitivity, lack of discrimination or biorelevance may warrant the use of non compendial methods. In this regard, the use of small volume dissolution methods offers strong advantages. The present study aims primarily to evaluate the dissolution performance of various drug products having different release mechanisms, using commercially available small volume USP2 dissolution equipment.

The present series of tests indicate that the small volume dissolution is a useful tool for the characterization of immediate release drug product. Depending on the release mechanism, different speed factors are proposed to mimic common one liter vessel performance. In addition, by increasing the discriminating power of the dissolution method, it potentially improves know how about formulations and on typical events which are evaluated during pharmaceutical development such as ageing or scale-up. In this regard, small volume dissolution is a method of choice in case of screening for critical quality attributes of rapidly dissolving tablets, where it is often difficult to detect differences using standard working conditions.
\end{abstract}


Key words: Dissolution; Small volume; Discrimination; Screening; Quality By Design

\section{Introduction}

Dissolution testing is a core performance test in pharmaceutical development and quality control. Dissolution testing has more and more evolved to establish relationships with in vivo performance or with manufacturing Critical Quality Attributes (CQA) in the scope of Quality by Design (QbD)[1].. The overall goal is to better control product performance within the life cycle of a product. For this purpose, the use of the classical USP dissolution working conditions using a one liter vessel with basket (respectively USP1) and paddle (respectively USP2) are well established [2,3] and are used as the first choice for development of a new dissolution method.

Nevertheless, limitations coming from the amount of material available, analytical sensitivity, lack of discrimination or biorelevance may warrant the use of non compendial methods. In particular, in early phase development, during screening of drug candidates, formulation is often developed for studies in animals and dissolution should be ideally conducted using media simulating the gastrointestinal environment as well as in volumes in line with the animal physiology [4]. Another case in which a classical method is not well suited is for low dose drugs or if the analytical method is not sensitive enough to detect the amount of dissolved drug precisely due to low concentration of the drug in the formulation [5]. To overcome those problems the concept of small-volume dissolution arose recently due to the possibility of using smaller sample sizes and smaller volumes of media, offering various advantages in view of substance and material consumption [6] and can serve as a valuable tool for dosage form screening [7] or formulation selection in animals.

The present study aims primarily to evaluate the potential of commercially available small volume USP2 dissolution equipment for the dissolution of solid drug product. This miniaturized vessel/paddle equipment can be easily fitted, without hardware change or adaptation, on a classical USP2 system. For this purpose, different kinds of dissolution release mechanisms for solid drug products; immediate release (IR), extended release (ER) as well as low dose tablets, were screened using both standard (one liter) and small volume dissolution setup. Working conditions to achieve the same dissolution performance for both tests were sought using the small volume equipment. Attempts to generalize these dissolution working conditions for new products are discussed. The discriminating power of the method is stressed through one example of IR tablets by comparing the contribution of the small vessel dissolution on typical events faced during development such as aging and scale-up versus compendial apparatus.

\section{Experimental Section}

\subsection{Materials}

Phosphate buffer, sodium chloride, 37\% hydrochloric acid (fuming), 85\% ortho-phosphoric acid, ethanol (99.9\%) as well as HPLC grade methanol were purchased from Merck (Darmstadt, Germany). Water was obtained from a Milli-Q (Millipore, Milford, MA, USA) water purification system. For all tests, GR grade material was used. 


\subsection{Methods}

Dissolution experiments were performed using a Sotax AT7 smart apparatus (Sotax, Allschwill, $\mathrm{CH})$. The small volume vessel is based on the USP one liter vessel setup, the size was reduced to be used with $50 \mathrm{~mL}$ to $200 \mathrm{~mL}$ of dissolution medium with an internal diameter of $40 \mathrm{~mm}$. The Sotax small volume vessel is a single device and offers the advantage to be installed directly on existing equipment. A small paddle blade of $29 \mathrm{~mm}$ length fitted at $10 \mathrm{~mm}$ from bottom of the vessel is used. An overview of the small volume set up is presented Figure 1 and the different sizes of the small volume equipments are listed in Table 1. The investigations were conducted in $150 \mathrm{~mL}$, working conditions that allow providing sink condition for all tested products.

Figure 1. A small volume vessel equipped with small paddle (right side) and the compendial one liter vessel with paddle (left).

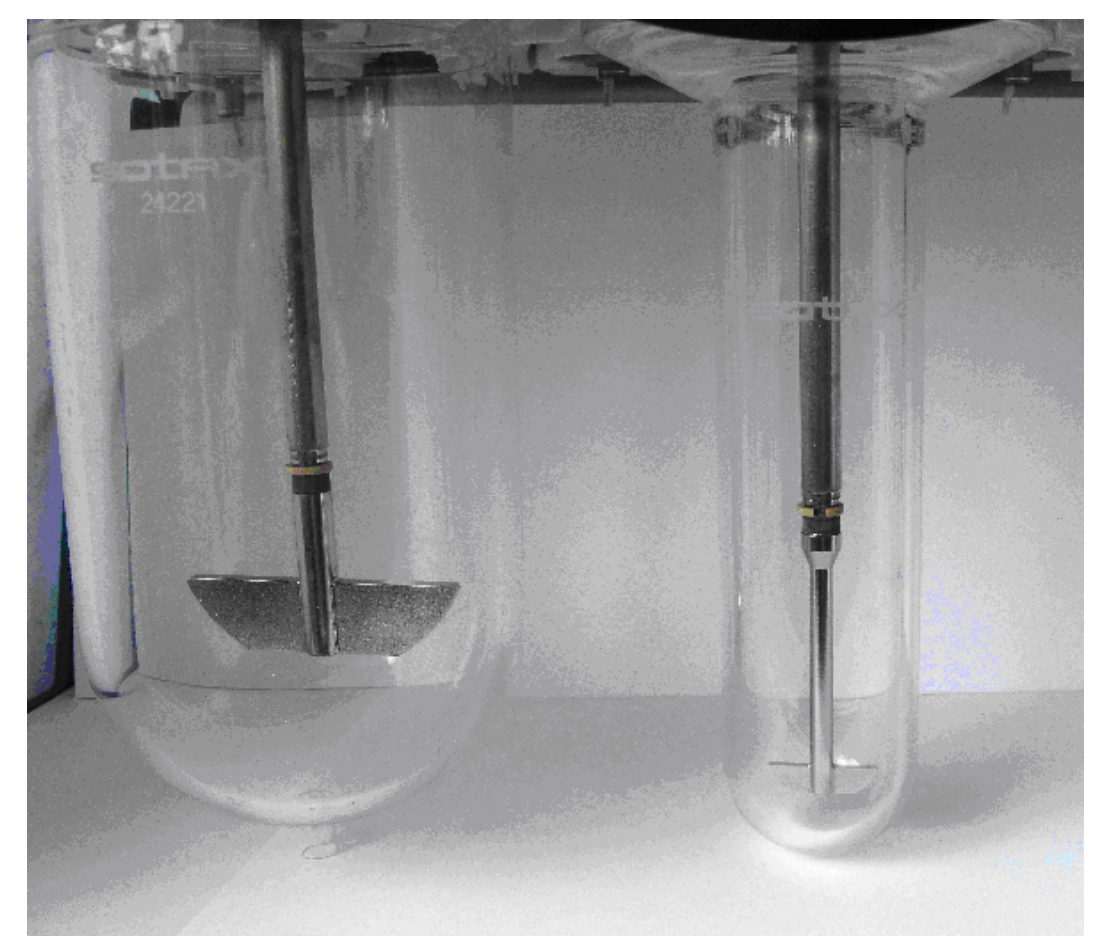

The aim of the series of tests was to establish a relationship between the reference one liter vessel method (using $900 \mathrm{~mL}$ or $500 \mathrm{~mL}$ of media) and the small vessel accessories (composed of small vessel and small paddle). For this purpose, the rotation speed of the small vessel system was varied from $50 \mathrm{rpm}$ up to $150 \mathrm{rpm}$ to evaluate the speed factor ( $\mathrm{s}$ ) between both methods. All the tests were performed in triplicate for screening purposes and with 6 units during the evaluation of scale-up and ageing with one example in order to confirm the early findings and assess the potential of the method during development. An overview of the dissolution working conditions for the classical one liter dissolution method is presented Table 2. The samples were collected semi automatically, filtrated and measured according to USP or by validated UV or HPLC methods. For all tests the same dissolution system was used. 
Table 1. Dissolution - Difference in Dimension (mm) of the small and USP Vessels and Paddle.

\begin{tabular}{|l|c|c|}
\hline & USP one liter vessel & Small volume Apparatus \\
\hline Vessel & & 185 \\
\hline Height & $168 \pm 8$ & 40 \\
\hline Internal diameter & $102 \pm 4$ & 29 \\
\hline Paddle & & 18 \\
\hline Blade Upper chord & $74.0 \pm 0.5$ & 7.5 \\
\hline Blade Lower chord & $42.0 \pm 1.0$ & 10 \\
\hline Height & $19.0 \pm 1.0$ & \\
\hline Distance from the bottom & $25 \pm 2$ & \\
\hline
\end{tabular}

\subsection{Model compounds}

Five different products exhibiting different type of release rates were chosen. Both Performance Verification Test tablets (prednisone [8] and salicylic acid [9], disintegrating and non disintegrating tablets respectively) were bought at USP, Rockville USA. Experimental IR formulations and ER tablet formulations were supplied by Roche Pharmaceutical Research department, Basel, CH. The ER tablets formulations were produced by wet granulation using different amounts of HPMC to achieve four hour (ER4H) and eight hour (ER8H) release profiles. The IR formulations are either immediate release, low dose tablet (IR(1)) or a very rapidly dissolving tablet IR(2), both exhibiting 85\% dissolved within 15 minutes in classical conditions.

The Active Pharmaceutical Ingredient (API)'s of these five drug products exhibit high or low solubility according to the biopharmaceutical classification system (BCS)[10]. However, the medium chosen during these investigations were set up in order to reach sink conditions in $150 \mathrm{ml}$. For each product, the same medium was used for the one liter and for the small vessel. An overview of the tablet types and properties is listed in Table 2.

Table 2. Overview of the tablets and release mechanisms tested using both dissolution methods.

\begin{tabular}{|l|c|c|c|l|c|c|}
\hline \multicolumn{1}{|c|}{ Product } & $\begin{array}{c}\text { Strength } \\
\text { (mg) }\end{array}$ & $\begin{array}{c}\text { BCS } \\
\text { class }\end{array}$ & \multicolumn{2}{c|}{$\begin{array}{c}\text { Dissolution method } \\
\text { with one liter vessel }\end{array}$} & $\begin{array}{c}\text { Release } \\
\text { mechanism }\end{array}$ & $\begin{array}{c}\text { Tablets } \\
\text { types }\end{array}$ \\
\hline $\begin{array}{l}\text { Prednisone } \\
\text { Batch :POE203 }\end{array}$ & $10 \mathrm{mg}$ & 1 & $500 \mathrm{~mL}$ & Paddle $50 \mathrm{rpm}$ & IR & Disintegrating \\
\hline $\begin{array}{l}\text { Salicylic acid } \\
\text { Batch :Q0D200 }\end{array}$ & $300 \mathrm{mg}$ & 3 & $900 \mathrm{~mL}$ & Paddle $100 \mathrm{rpm}$ & ER & Non-disintegrating \\
\hline ER4H / ER8H & $1 \mathrm{mg}$ & $2^{*}$ & $500 \mathrm{~mL}$ & Paddle $50 \mathrm{rpm}$ & ER & Erosion-Diffusion \\
\hline IR(1) & $0.075 \mathrm{mg}$ & 1 & $500 \mathrm{~mL}$ & Paddle $50 \mathrm{rpm}$ & IR & Disintegrating \\
\hline $\mathrm{IR}(2)$ & $50 \mathrm{mg}$ & $2^{*}$ & $900 \mathrm{~mL}$ & Paddle $50 \mathrm{rpm}$ & IR & Disintegrating \\
\hline
\end{tabular}

$\mathrm{ER}=$ Extended Release; $\mathrm{IR}=$ Immediate Release; $*$ Active principle having $\mathrm{pH}$ dependent solubility. Medium was chosen to provide sink condition in $150 \mathrm{~mL}$.

For IR(2), comparison after storage for three months at $25{ }^{\circ} \mathrm{C} / 60 \%$ relative humidity (r.h.) and $40{ }^{\circ} \mathrm{C} / 75 \%$ r.h. according to ICH conditions and after scale-up (8 $\mathrm{kg}$ to $15 \mathrm{~kg}$ ) were performed using both methods. 


\subsection{In vitro dissolution test comparison}

For the screening purpose of the study, in addition to a visual comparison of the dissolution profiles, where the shape and the plateau of the curves were estimated, the closeness of the profiles was assessed by calculating the ratio of percent dissolved at each time point according to equation 1 and the mean ratio for all sampling points was assessed using equation 2.

$$
\begin{aligned}
& \Theta(\mathrm{t})=\mathrm{D}_{\text {small }}(\mathrm{t}) / \mathrm{D}_{\text {ref }}(\mathrm{t}) \\
& \Theta_{\text {mean }}=\frac{\sum_{t=1}^{n} R(t)}{n}
\end{aligned}
$$

$\Theta(t)$ represents the ratio at time $t, D_{\text {small }}$ the percent dissolved for the small volume method and $D_{\text {ref }}$ the percent dissolved for the reference method (so called one liter). $\Theta_{\text {mean }}$ represents mean of the $\Theta(t)$.

A $\Theta_{\text {mean }}$ close to one is sought with a ratio stable all along the profile. $\Theta_{\text {mean }}$ above one would mean that the profiles have the tendency to be faster than the reference. $\Theta_{\text {mean }}$ below one would mean that the profiles have the tendency to be slower than the reference. Applying such a ratio assumes that the dissolution curves exhibit similar profiles with only a difference in the rate of dissolution. The f2 factors [11] were calculated on the mean dissolution values as an additional factor to the $\Theta_{\text {mean }}$.

\section{Results and Discussion}

Figures 2 to 8 show the mean dissolution profiles of all tested variants and Table 3 shows the mean of the ratios. Similar findings were found for the ratios and the $\mathrm{f} 2$ factors. No coning or mounting was observed using the small volume vessel except for the prednisone disintegrating tablets, which was also seen for the one liter vessel. Similar curve shapes were observed for prednisone, salicylic acid as well as for ER tablets. Slightly different curves shape and time to reach the plateau were observed for the IR(1) and IR(2) tablets. For all dissolution experiments, the observed standard deviations (SD) are low (maximum of $6 \%$ at first sampling point and below $5 \%$ for the next sampling points). The SD are similar for both small volume and one liter methods through the entire profiles.

Table 3. Mean of ratio $\left(\Theta_{\text {mean }}\right)$ percent dissolved between small and one liter dissolution at different rotation speeds. Best values are in bold.

\begin{tabular}{|l|l|c|c|c|c|c|c|}
\hline \multirow{2}{*}{ Product } & \multirow{2}{*}{ Reference Method } & \multicolumn{7}{|c|}{ Small vessel rotation speed } \\
\cline { 3 - 8 } & & $\mathbf{5 0} \mathbf{~ r p m}$ & $\mathbf{7 5} \mathbf{~ r p m}$ & $\mathbf{1 0 0} \mathbf{~ r p m}$ & $\mathbf{1 1 0} \mathbf{~ r p m}$ & $\mathbf{1 2 5} \mathbf{~ p m}$ & $\mathbf{1 5 0} \mathbf{~ r p m}$ \\
\hline Prednisone & Paddle 50 rpm & 0.39 & 0.48 & 0.67 & $0.85^{*}$ & $\mathbf{1 . 0 5}^{*}$ & - \\
\hline Salicylic acid & Paddle $100 \mathrm{rpm}$ & - & - & $0.76^{*}$ & - & - & $\mathbf{0 . 9 6}^{*}$ \\
\hline ER4H & Paddle 50 rpm & $0.93^{*}$ & - & $\mathbf{0 . 9 8}^{*}$ & - & - & - \\
\hline ER8H & Paddle 50 rpm & $1.01^{*}$ & - & $\mathbf{1 . 0 5}^{*}$ & - & - & - \\
\hline IR(1) & Paddle 50 rpm & 0.59 & 0.79 & $0.95^{*}$ & - & $\mathbf{0 . 9 8 *}$ & - \\
\hline IR(2) & Paddle 50 rpm & 0.57 & 0.71 & 0.86 & - & $\mathbf{0 . 9 9 *}$ & - \\
\hline
\end{tabular}

* indicates the $\mathrm{f} 2$ factors between small and one liter vessel with a value above 50 .

When using an identical rotation speed, the small volume vessels showed a lower percent of drug dissolved than the one liter vessel for most of the methods except for the slowest ER8H using the paddle at $50 \mathrm{rpm}$. 
For prednisone (Figure 2), a small vessel/paddle at $125 \mathrm{rpm}$ resulted in a similar profile compared to the USP paddle $50 \mathrm{rpm}$ method. This corresponds to a speed factor ( $\mathrm{sf}$ ) of 2.5 ( $\mathrm{sf}=2.5$ ).

Figure 2. Dissolution profiles for prednisone tablets with small vessel accessories versus USP method with one liter vessel.

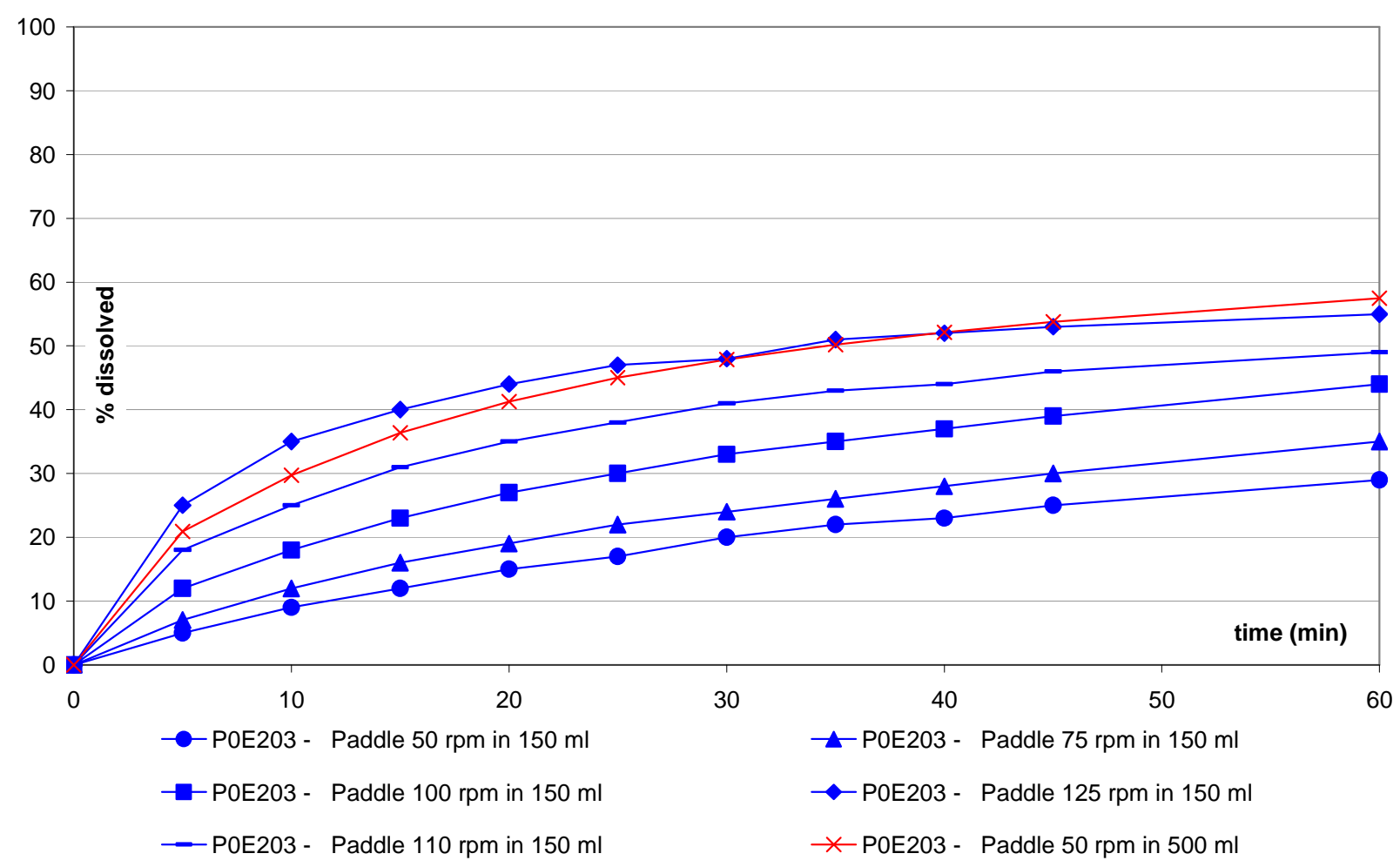

For salicylic acid non-disintegrating tablets (Figure 3), a small vessel/paddle at $150 \mathrm{rpm}$ results in a similar profile to the USP paddle $100 \mathrm{rpm}$ method $(\mathrm{sf}=1.5)$.

Figure 3. Dissolution profiles for salicylic acid tablets with small vessel accessories versus USP method with one liter vessel.

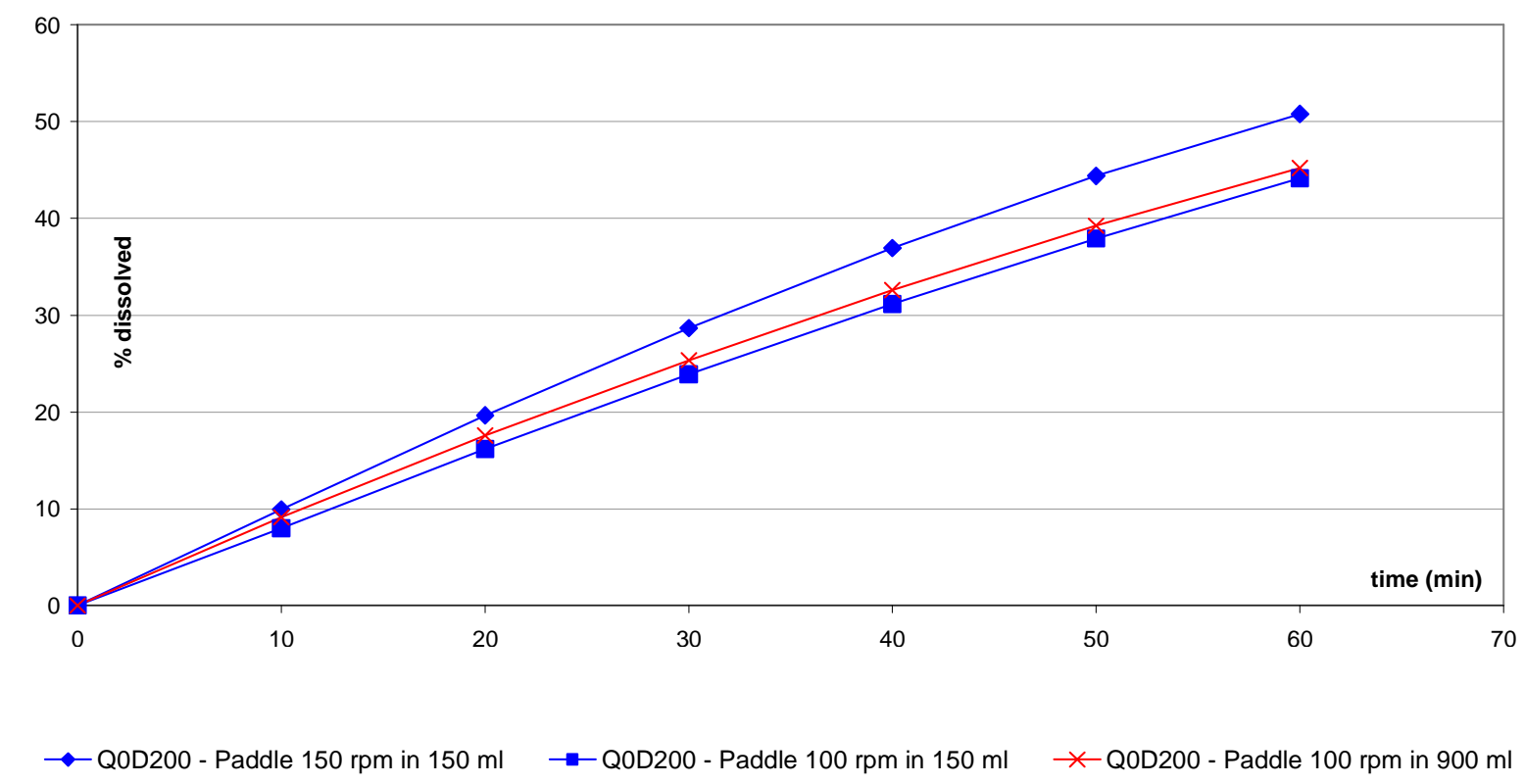


For the extended release tablets ER4H and ER8H (Figure 4), the impact of the small vessel/paddle setup is less pronounced. By varying the rotation speed from 50 to $100 \mathrm{rpm}$, similar profiles can be observed and the ratios remain very close.

Figure 4. ER4H and ER8H tablets: comparison of small vessel accessories versus one liter vessel.

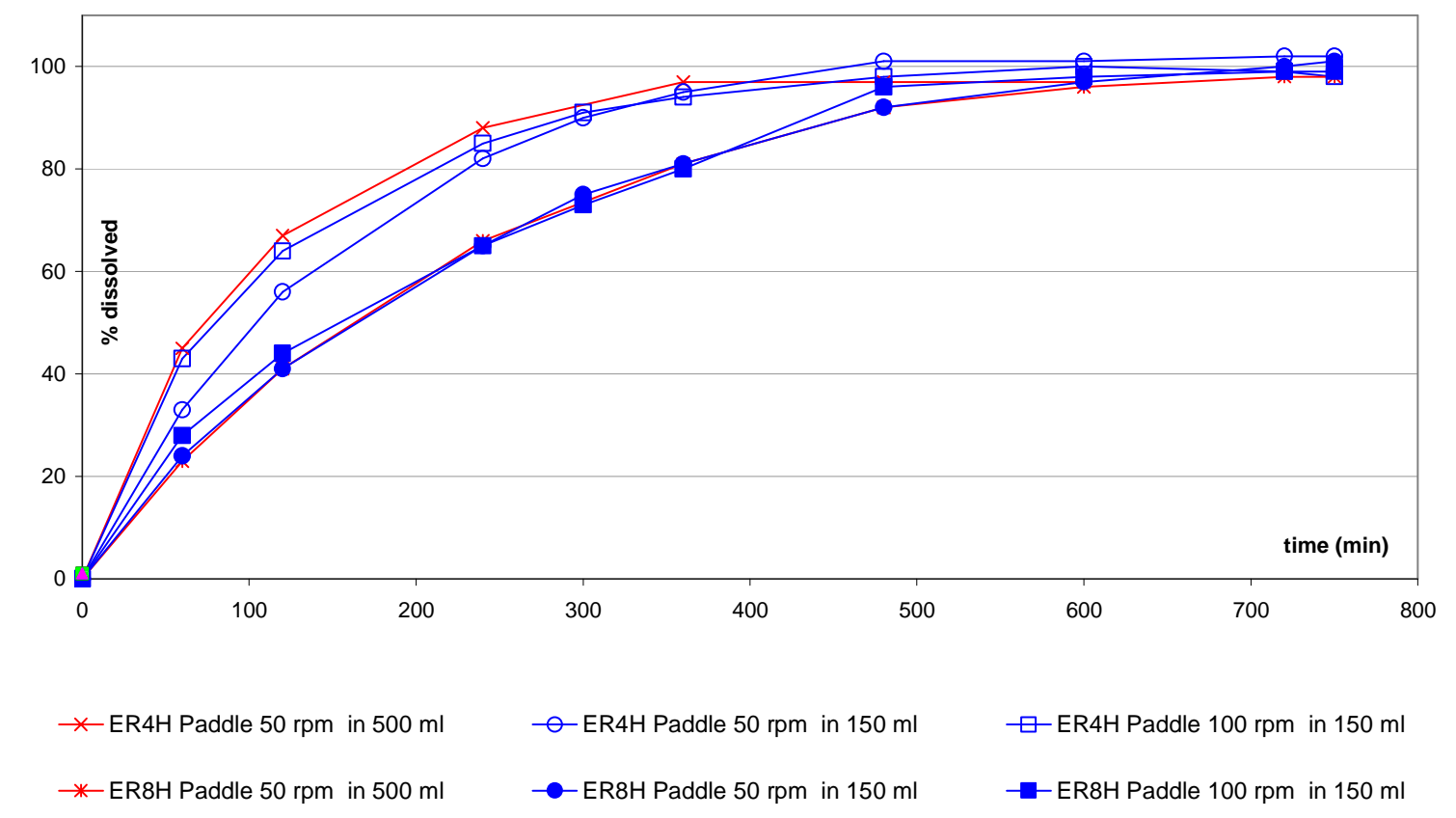

For the IR(1) tablets (Figure 5), both motion speeds of $100 \mathrm{rpm}$ and $125 \mathrm{rpm}$ when using the small vessel/paddle resulted in a similar profile to the one liter method with paddle at $50 \mathrm{rpm}(\mathrm{sf}=2.5)$.

For the IR(2) tablets (Figure 6), use of the small vessel/paddle at $125 \mathrm{rpm}$ resulted in a similar profile to the one liter method at paddle $50 \mathrm{rpm}$ method $(\mathrm{sf}=2.5)$.

Figure 5. IR(1) tablets: comparison of small vessel accessories versus one liter vessel.

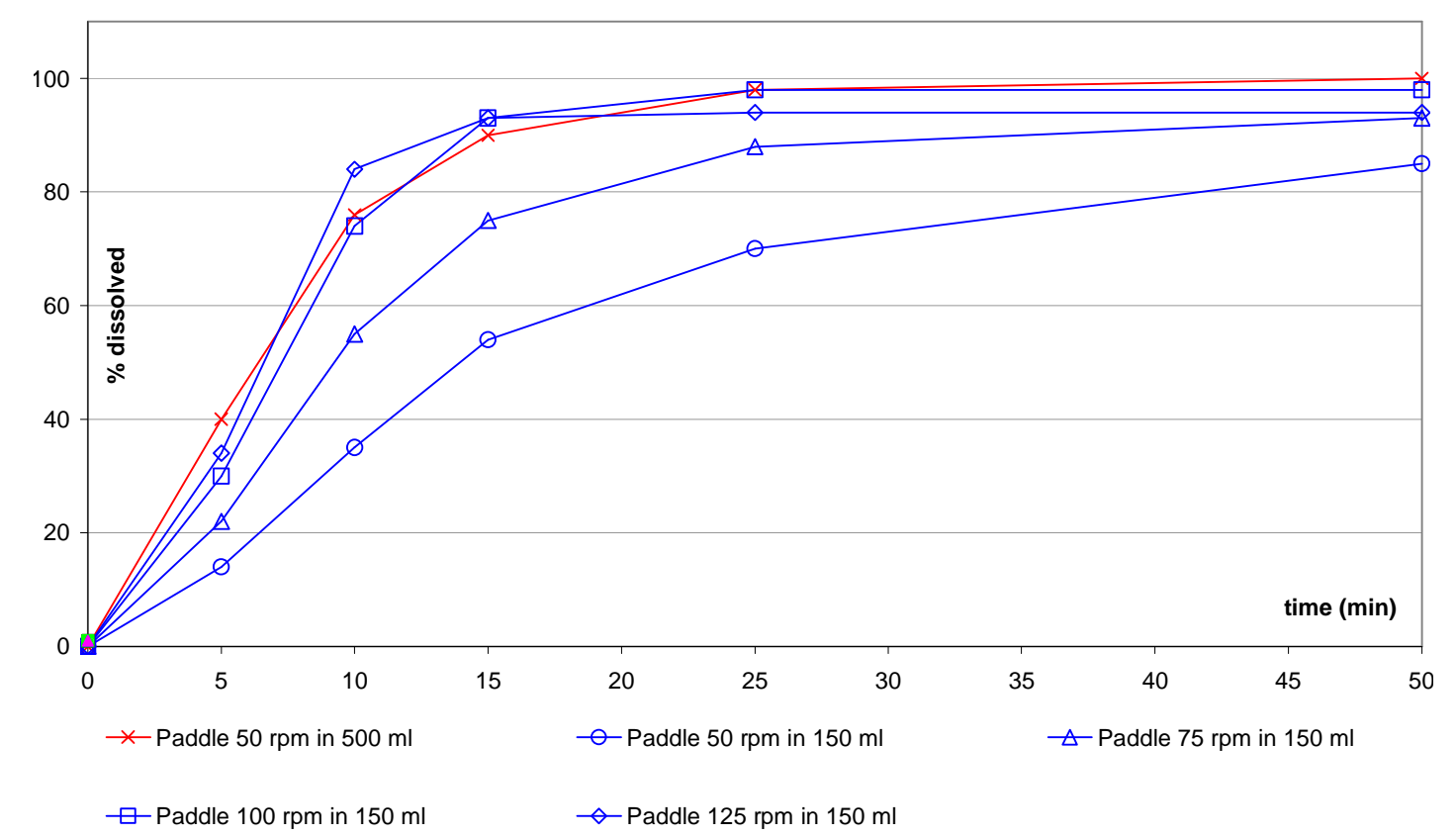


Figure 6. IR(2) tablets: comparison of small vessel accessories versus one liter vessel.

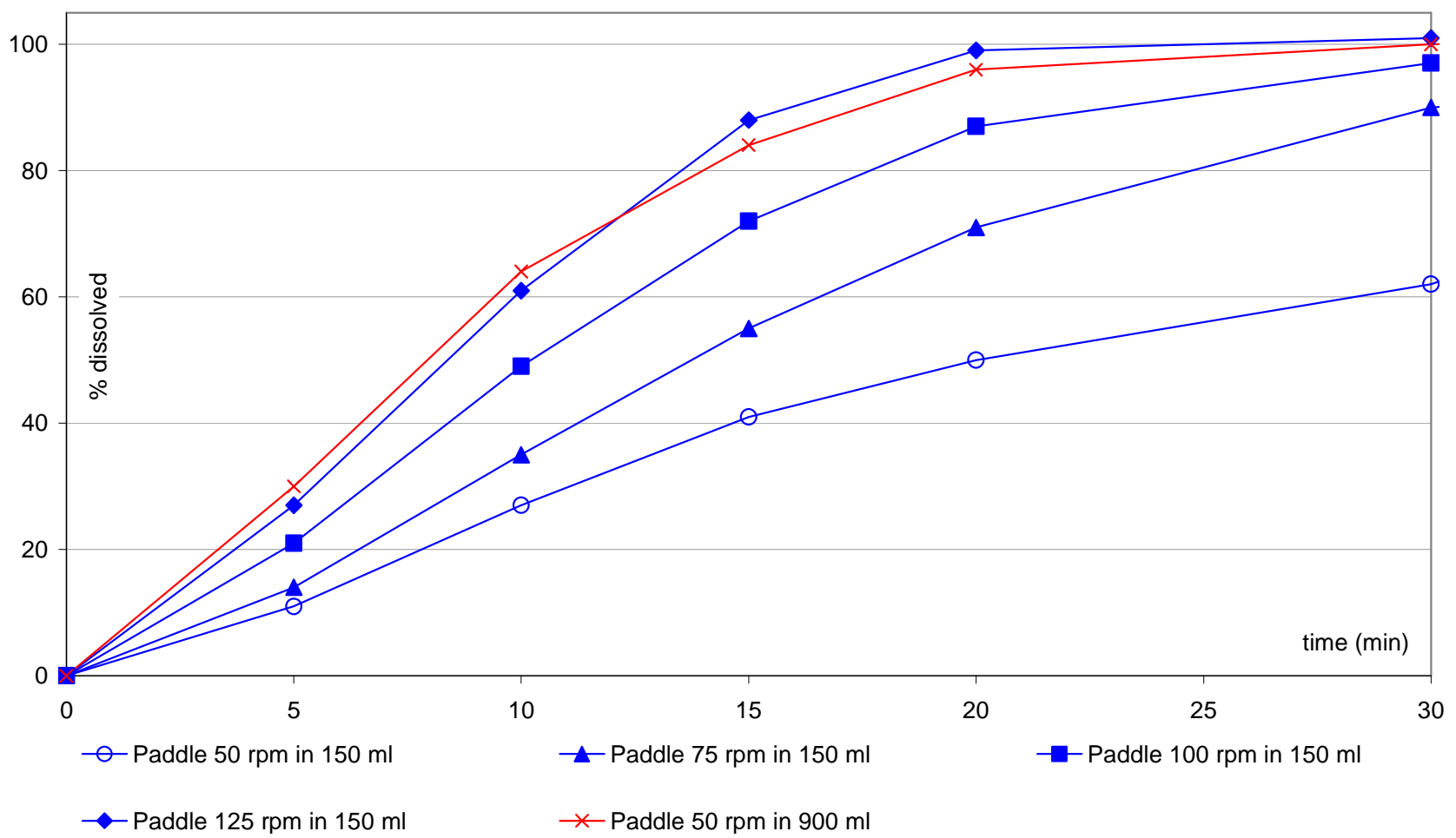

The comparison of samples after storage (Figure 7) does not show a difference, whereas after scaleup (Figure 8) a new trend is visible only using the small vessel at $50 \mathrm{rpm}$.

Figure 7. IR(2) tablets: comparison after scale-up using small vessel accessories.

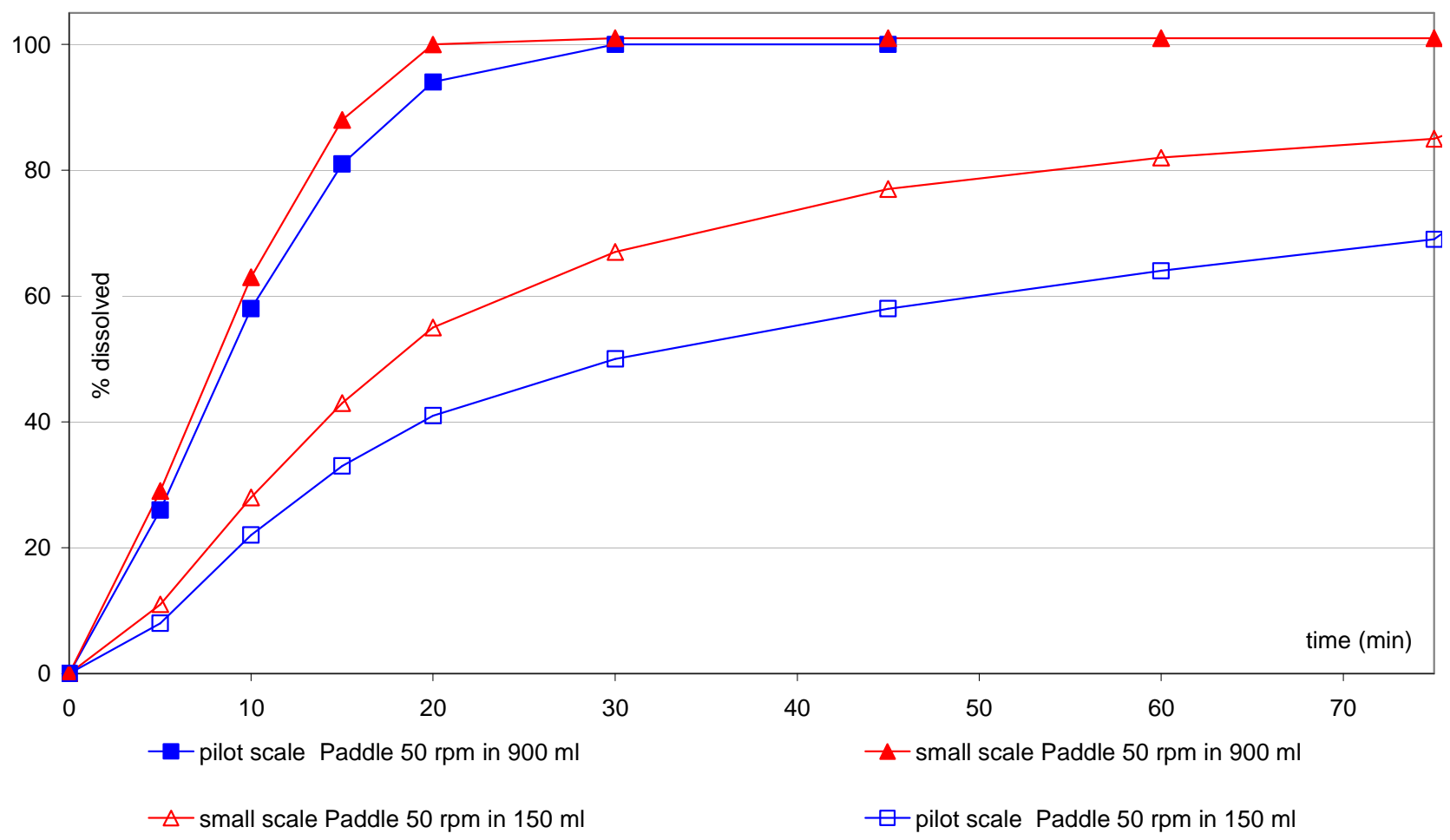


Figure 8. IR(2) tablets: comparison after storage using small vessel accessories.

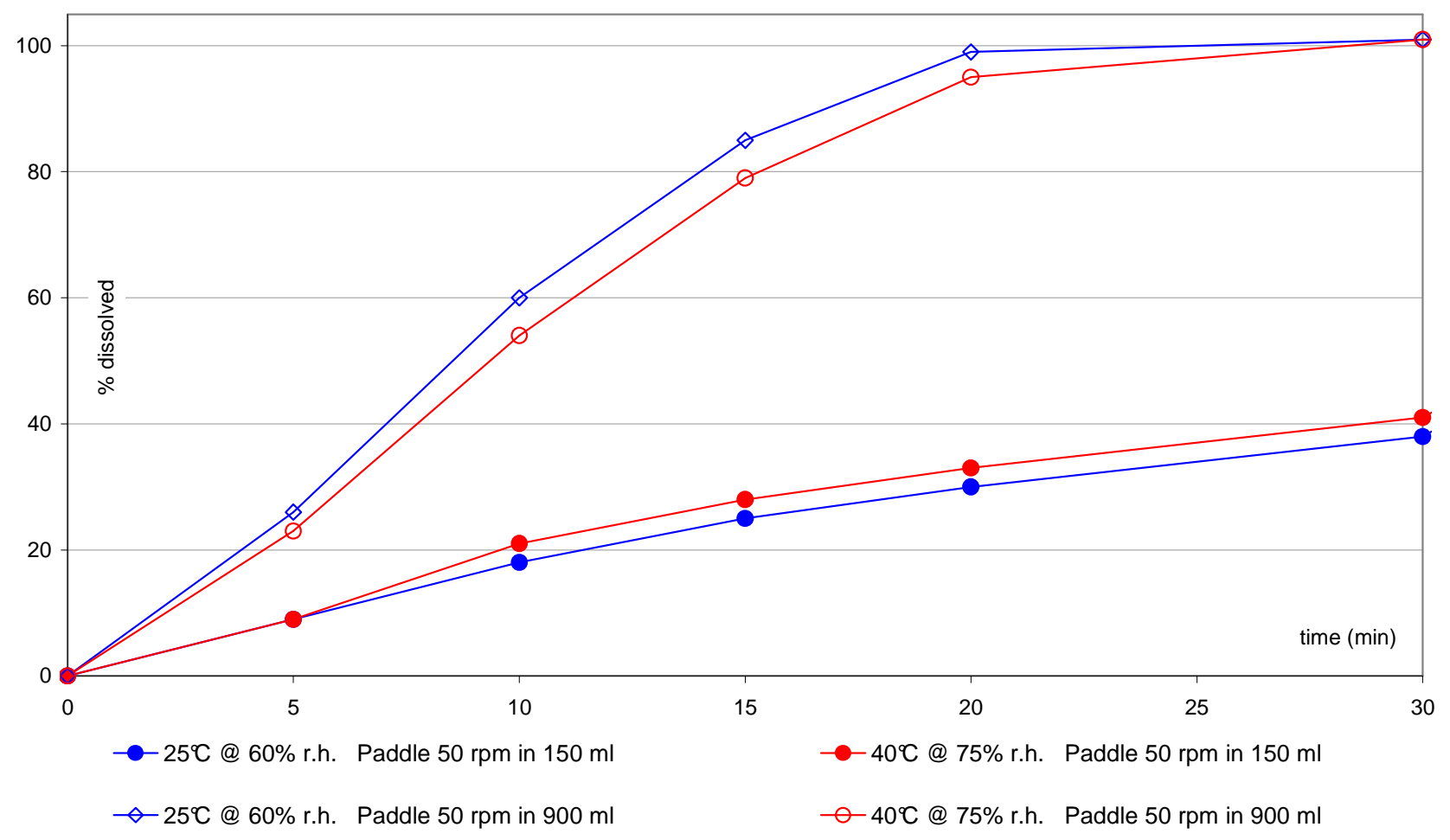

All those results are summarized in Table 4.

Table 4. Found rotation speed factors using small vessel versus one liter vessel to reach the same performance.

\begin{tabular}{|c|c|c|c|c|c|}
\hline Tablet type & Product & $\begin{array}{c}\text { Dissolution } \\
\text { method }\end{array}$ & $\begin{array}{c}\text { Rotation } \\
\text { speed using } \\
\text { one liter vessel }\end{array}$ & $\begin{array}{c}\text { Rotation } \\
\text { speed using } \\
\text { small vessel }\end{array}$ & $\begin{array}{c}\text { Rotation speed } \\
\text { Factor (sf) }\end{array}$ \\
\hline disintegrating & Prednisone & Paddle & 50 & 125 & 2.5 \\
\hline disintegrating & IR(1) & Paddle & 50 & 125 & 2.5 \\
\hline disintegrating & IR(2) & Paddle & 50 & 125 & 2.5 \\
\hline $\begin{array}{c}\text { Non- } \\
\text { disintegrating }\end{array}$ & Salicylic acid & Paddle & 100 & 150 & 1.5 \\
\hline $\begin{array}{c}\text { Non } \\
\text { disintegrating }\end{array}$ & ER4H & Paddle & 50 & $50-100$ & $1-2$ \\
\hline $\begin{array}{c}\text { Non } \\
\text { disintegrating }\end{array}$ & ER8H & Paddle & 50 & $50-100$ & $1-2$ \\
\hline
\end{tabular}

These investigations clearly showed that using the small vessel set up, equivalent or higher rotational speeds are necessary to obtain similar dissolution rates when compared to the one liter vessel. Speed factors from 1 to 2.5 have been observed (see Table 4).

A theoretical calculation of the rotation speed needed for the small paddle to reach the velocity of the large paddle at $50 \mathrm{rpm}$ was performed based on the differences of the paddle sizes (Table 5) [12]. A corresponding rotation speed of 121 to $129 \mathrm{rpm}$ was found. This difference corresponds to a speed factor of 2.5. 
Table 5. Theoretical calculation of hydrodynamics difference between small paddle and large paddle.

\begin{tabular}{|c|c|c|c|c|c|c|}
\hline & & Equation & $\begin{array}{r}\text { Length } \\
\text { F }\end{array}$ & $\begin{array}{l}\text { p of the } \\
\text { e }\end{array}$ & $\begin{array}{r}\text { Length } \\
\text { the }\end{array}$ & $\begin{array}{l}\text { tttom of } \\
\text { dle }\end{array}$ \\
\hline & & & small & large & small & large \\
\hline Rotation/rpm & $\mathrm{R}$ & & 100.00 & 50.00 & 100.00 & 50.00 \\
\hline Frequency/Hz & $\mathrm{F}$ & $\mathrm{R} / 60$ & 1.67 & 0.83 & 1.67 & 0.83 \\
\hline Periodicity/s & $\mathrm{T}$ & $1 / \mathrm{F}$ & 0.60 & 1.20 & 0.60 & 1.20 \\
\hline Angular velocity $/ \mathrm{rad} \cdot \mathrm{s}^{-1}$ & $\mathrm{~W}$ & $2 \mathrm{pi} / \mathrm{T}$ & 10.51 & 5.25 & 10.51 & 5.25 \\
\hline $1 / 2$ lenght $/ \mathrm{mm}$ & $\mathrm{R}$ & & 14.50 & 37.25 & 8.70 & 21.00 \\
\hline $\begin{array}{l}\text { Linear speed on top of the } \\
\text { paddle } / \mathrm{cm} \cdot \mathrm{s}^{-1}\end{array}$ & $\mathrm{~V}$ & $\mathrm{R} * \mathrm{~W}$ & 152.33 & 195.66 & 91.40 & 110.31 \\
\hline $\begin{array}{l}\text { Calculation of the angular } \\
\text { velocity for the small } \\
\text { paddle/rad } \cdot \mathrm{s}^{-1}\end{array}$ & $\mathrm{~W}$ & & 13.49 & & 12.68 & \\
\hline Periodicity/s & $\mathrm{T}$ & & 0.47 & & 0.50 & \\
\hline Frequency/Hz & $\mathrm{F}$ & & 2.15 & & 2.02 & \\
\hline & & & 128.86 & $\geq 129$ & 121.07 & $\geq 121$ \\
\hline
\end{tabular}

A speed factor of 1.5 was observed for salicylic acid tablets and 1 to 2 for the ER formulations. A speed factor of 2.5 was observed for the IR formulations (prednisone, IR(1) and IR(2)) indicating that the working conditions to obtain the performance of one liter vessels in small vessels clearly depend on the type of release mechanism.

In the case of the fast dissolving IR formulation, as presented in this paper, one of the main factors to take into account beside the intrinsic properties of the API (e.g., solubility) is the rate of renewal of the dissolution media in contact with the API. Based on Noyes Whitney equation [13] and diffusion layer term $[14,15]$, it is directly in relation to the rotation speed of the dissolution method.

In case of the salicylic acid tablets or the ER formulations, the limiting factor is not driven only by dissolution properties of the API but rather by the design of the formulation (e.g., erosion/diffusion [16]) and, therefore the characteristics of the formulation are less dependent on the renewal of the media as soon as this renewal is faster than the release rate [17-19] This phenomenon is emphasized in vitro for the longer releasing tablets. In our example for the ER8H, no difference could be observed between both methods and that independently of the rotation speed in small vessels. Diffusion controlled tablets would then not be impacted by the hydrodynamics [20] and the speed factor may come close to 1 .

For tablets impacted by small volumes, a higher discriminating power may be expected by measuring of rapidly dissolving tablets using a small vessel at $50 \mathrm{rpm}$ or less. In this case, $50 \mathrm{rpm}$ in a small vessel would correspond approximately to $20 \mathrm{rpm}$ (50 rpm divided by sf 2.5 ) in a one liter vessel, which would be out of the range of standard performance verification test of the apparatus.

Based on this observation, further investigations were tried with the IR(2) tablets. At 50 rpm with the small vessel/paddle, the differences after manufacturing scale-up are more pronounced than with the one liter vessel (Figure 7), whereas no significant change can be observed after storage under different temperatures (Figure 8). These differences highlight a possible change of the intrinsic quality of the tablets after manufacturing scale-up, whereas the product seems to be very stable after three months storage even under stress storage conditions and using the most discriminating dissolution method. 
The significance of the observed difference does not mean that a change in in vivo performance should be expected, the profiles remain very rapidly dissolving and both tablets should be completely dissolved before gastric emptying [21]. However, this difference points out a change in the tablets' properties after scale-up and further investigations into manufacturing parameters and resulting solid state properties may be initiated. In this regard, the small vessel dissolution method supports a better process understanding and is in line with a QbD approach.

Results from the present series of tests indicated that the small paddle apparatus might be a useful tool in characterizing drug release profiles under standard test conditions, mainly to IR and disintegrating tablets as it was shown to be more discriminant.

Takano et al [22] showed that small volumes can also be applied for low soluble molecules even under non sink conditions

During development of the small volume method, it is important to take into account that the current small or low volume vessels are non compendial. The commercially available vessels are well defined [23] but there are still differences from supplier to supplier. It was demonstrated that differences in the actual compendia apparatuses existed between suppliers even if within the standardized dimensions and that those differences marginally affected the results [24]. In case of small volume vessels there is no currently fixed dimension between suppliers. This means that each investigation should be carry out specifically and that transfer is more complicated than using the classical pharmacopeia one liter vessel.

The discriminating power of the small volume method seems more pronounced for IR compared to ER formulations. It is therefore recommended to systematically integrate small volume methods in the screening of new methods for IR formulation.

\section{Conclusion}

This limited set of data clearly showed that the small volume apparatus is a useful tool in the characterization of solid drug product dissolution profiles. It can be easily installed in a standard laboratory, it uses standardized working conditions and can be set up to fit to the common one liter vessel performance when the dissolution method is not rugged enough for instance with an analytical method having an improper sensitivity. In addition beside the advantage of using smaller volumes of media, it potentially allows to expand the discriminating power of a method by applying gentle agitation which is particularly important for IR and disintegration tablets. Only two IR tablets within sink conditions were exemplified and further tests should be initiated to consolidate these first outcomes. Nevertheless these data taken as a starting point showed that this approach improves know how about formulations, the process and is a method of choice instances of screening for CQA of rapidly dissolving tablets where it is often difficult to detect difference using standard working conditions.

\section{Conflict of Interest}

There is no conflict of Interest. 


\section{Acknowledgement}

The authors acknowledge: C. Keiflin, P. Wininger, C. Maureta, M. Brach, Y. Ducommun for technical assistance and B. Fischer for managerial support.

\section{References and Notes}

1. International committee of harmonisation of technical requirements for registration of pharmaceuticals for human use. Harmonised Tripartite Guideline. Q8: Pharmaceutical Development. In Proceedings of International Conference on Harmonisation, Geneva, Switzerland, 18 November 2004.

2. EP. European Pharmacopoeia. 2.9.3: Dissolution for Solid Oral Dosage Forms. The Council of Europe (European Directorate for the Quality of Medicines \& Healthcare): Strasbourg, France, 2009.

3. USP. The United States Pharmacopeia 2009 (USP 32). Convention, Inc.: Rockville, MD, USA, 2009; Chapter 711, 724.

4. Gu, C.H.; Gandhi, R.B.; Tay, L.K.; Zhou, S.; Raghavan, K. Importance of using physiologically relevant volume of dissolution medium to correlate the oral exposure of formulations of BMS480188 mesylate. Int. J. Pharm. 2004, 269, 195-202.

5. Avdeef, A. Solubility of Sparingly Soluble Ionizable Drugs. Adv. Drug Deliv. 2007, 59, 568-590.

6. Klein, S.; Shah, V. The Mini Paddle Apparatus a Useful Tool in the Early Developmental Stage? Experiences with Immediate-Release Dosage Forms. Dissolution Technol. 2006, 13, 6-11.

7. Wyttenbach, N.; Alker, A.; Grassmann, O.; Scheubel, E. Tenoxicam-Methhylparaben Cocrystal Formation in Aqueous Suspension Formulation. In Proceedings of 2009 AAPS Annual Meeting and Exposition, Los Angeles, CA, USA, October 7, 2009.

8. United States Pharmacopeia. Prednisone tablets RS. http://www.usp.org/pdf/EN/referenceStandards/prednisoneLot-P0E203.pdf/ (accessed on 21 October 2010).

9. United States Pharmacopeia. Salicylic Acid Tablets RS. http://www.usp.org/pdf/EN/referenceStandards/salicylicAcidTabletsLotQ0D200.pdf/ (accessed on October 21, 2010).

10. Amidon, G.; Lennernas, L.H.; Shah, V.P.; Crison, J.R. A Theoretical Basis for a Biopharmaceutic Drug Classification: The Correlation of In Vitro Drug Product Dissolution and In Vivo Bioavailability. Pharm. Res. 1995, 12, 413-420.

11. FDA. Guidance for Industry. Immediate Release Solid Oral Dosage Forms. Scale-up and Postapproval Changes: Chemistry, Manufacturing, and Controls, In vitro Dissolution Testing and In vivo Bioequivalence Documentation; US Food and Drug Administration, Center for Drug Evaluation and Research: Washington, D.C., USA, 1995. http://www.fda.gov/downloads/Drugs/GuidanceComplianceRegulatoryInformation/Guidances/ucm070636.pdf.

12. Lentner, C. Units of Measurement, Body Fluid, Composition of Body, and Nutrition. In Geigy Scientific Tables, 8 Sub ed.; Ciba Pharmaceutical Co.: Basel, Switzerland, 1981; Volume 1.

13. Noyes, A.; Whithney, W.R. The rate of solution of solid substances in their own solutions. J. Am. Chem. Soc. 1897, 19, 930-934. 
14. Brunner, E. Velocity of reaction in non-homogeneous systems. Zeit. physikal. Chem. 1904, 47, 56-102.

15. Emami, J. In vitro - in vivo correlation: from theory to applications. J. Pharm. Pharm. Sci. 2006, 9, 169-189.

16. Royce, A.; Li, S.; Weaver, M.; Shah, U. In vivo and in vitro evaluation of three controlled release principles of 6- $N$-cyclohexyl-2'-O-methyladenosine. J. Control. Release 2004, 97, 79-90.

17. Morihara, M.; Aoyagi, N.; Kaniwa, N.; Katori, N.; Kojim, S. Hydrodynamic flows around tablets in different pharmacopeias dissolution tests. Drug Dev. Ind. Pharm. 2002, 28, 655-662.

18. D'Arcy, D.M.; Corrigan, O.I.; Healy, A.M. Hydrodynamic simulation (CFD) of asymmetrically positioned tablets in the paddle dissolution apparatus: impact on dissolution rate and variability. $J$. Pharm. Pharmacol. 2005, 57, 1243-1250.

19. D'Arcy, D.M.; Corrigan, O.I.; Healy, A.M. Evaluation of hydrodynamics in the basket dissolution apparatus using computational fluid dynamics-Dissolution rate implications. Eur. J. Pharm. Sci. 2006, 27, 259-267.

20. Royce, A. In vivo and in vitro evaluation of three controlled release principles of 6-N-cyclohexyl2'-O-methyladenosine. J. Control. Release 2004. 97, 79-90.

21. Dickinson, P.A.; Lee, W.W.; Stott, P.W.; Townsend, A.I.; Smart, J.P.; Ghahramani, P.; Hammett, T.; Billett, L.; Behn, S.; Gibb, R.C.; Abrahamsson, B. Clinical relevance of dissolution testing in quality by design. AAPS J. 2008, 10, 2, 380-390.

22. Takano, R.; Sugano, K.; Higashida, A.; Hayashi, Y.; Machida, M.; Aso, Y.; Yamashita, S. Oral absorption of poorly water-soluble drugs: computer simulation of fraction absorbed in humans from a miniscale dissolution test. Pharm. Res. 2006, 23, 1144-1156.

23. Crist. G.B. Trends in small-Volume Dissolution Apparatus for Low Dose Compounds. Dissolution Technol. 2009, 16, 1.

24. Deng, G.; Ashley, A.J.; Brown, W.E.; Eaton, J.W.; Hauck, W.W.; Kikwai, L.C.; Liddell, M.R.; Manning, R.G.; Munoz, J.M.; Nithyanandan, P.; Glasgow, M.J.; Stippler, E.; Wahab, S.Z.; Williams, R.L. The USP Performance Verification Test, Part I: USP Lot P Prednisone Tablets: quality attributes and experimental variables contributing to dissolution variance. Pharm Res. 2008, 25, 1100-1109.

(C) 2010 by the authors; licensee MDPI, Basel, Switzerland. This article is an open access article distributed under the terms and conditions of the Creative Commons Attribution license (http://creativecommons.org/licenses/by/3.0/). 